\title{
Impact Of Internet In Education And Social Empowerment Of Women In Pakistan
}

\author{
M. Sadiq Ali Khan \\ Department of Computer Science \\ University of Karachi
}

\begin{abstract}
The Internet is one of the utmost current expansions in the globe of information technology and has turn into a functional apparatus that has cultivated the course of making the globe a worldwide community. Information Technology fulfils the communication gap and ensures the effective distance learning. Due to information technology the thought process of the person, especially in the education sector has been changed. People now are well aware of all the important technological aspects which can help them in their research area by means of strong search engines, research based tools and efficient analysis techniques. The medium is especially useful for empowerment of women in developing countries. The purpose of this research is to explore the impact of Internet usage on women in Pakistan. The result of study revealed that women in Pakistan are actively using the Internet for education, research and social interaction which gives them more active role in relatively a conservative society.
\end{abstract}

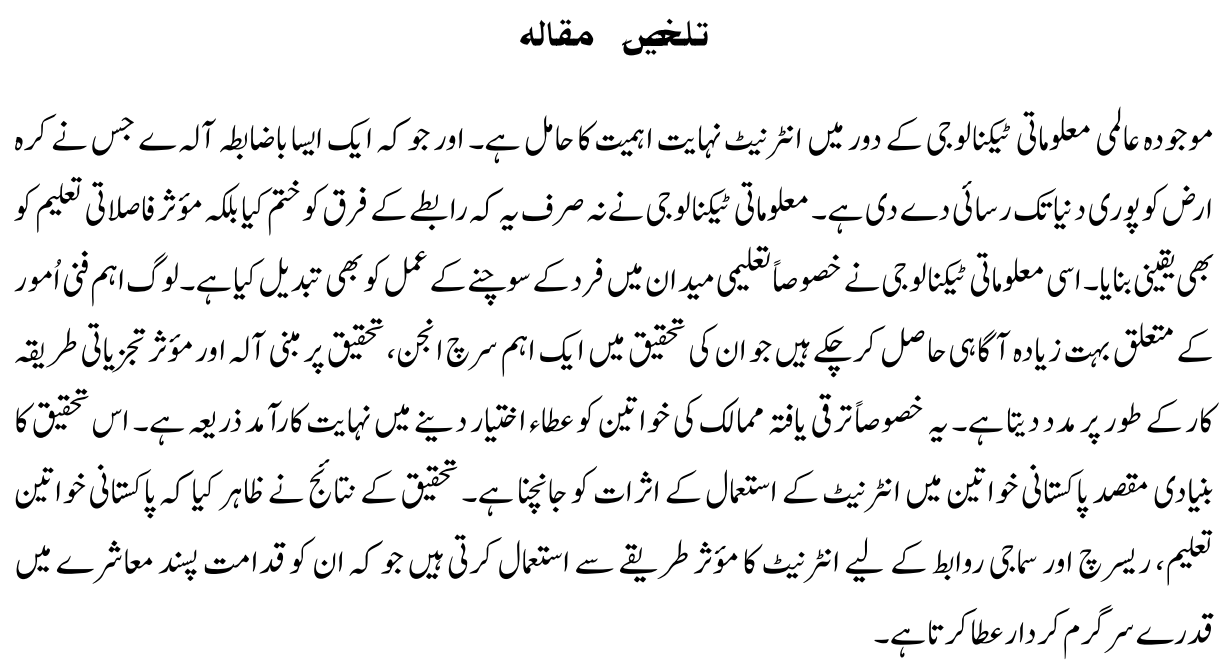

\section{Introduction}

The Internet has made the organizations capable to exchange information with other organizations internally or to communicate externally. The internet technology has provided us the primary infrastructure for e-commerce, e-banking, e-business, e-learning and virtual library. Various implementations of technology influence the values of a society and new technology often raises new ethical questions (Aycock, J. and J. Sullins, 
2010). Examples include the rise of the notion of efficiency in terms of human productivity, a term originally applied only to machines, and the challenge of traditional norms.

Today we are in the phase of changing the technological paradigm. Now the technology has become so small that billions of transistors and electronic circuits fabricated/installed in a tiny piece of silicon has more power and processing capabilities as compare to past era. When we talk about the term "internet", it means collection of thousands of networks which are interconnected to each other, and when we say the information is available on the internet, it means it is available for everyone to access and share at ease (Rehman et.al, 2010). Dial-up connections and Desktop PC are the things of the past and are no longer required as mobile phones and high speed wifi connections allows a user to retrieve and update information in seconds regardless of wherever they are (H.Bouwman et.al, 2012). If we consider the first 50 million users, the television took 13 years, internet took 4 years and face book needed only 2 years to cover and grasp this entire community. Social media is about interacting and sharing information with others online. People can use their laptop, PDA's palmtops and their mobile phones to connect with the social world and share their views with a single touch.

\section{a) Information}

Information is knowledge derived from study, experience, or instruction. Any data which has meaning is considered as information (Park, Y et.al, 2011). Information is simply a knowledge which is received or sent through study, research, communication, etc. Internet is the way to get information where the best thing is that information availability according to everyone perspective. Any type of information is available on internet specially for women all types of information is available on internet any problem from a women's kitchen to her life can be solved by internet now life become much more easy by all that information available on the internet.

\section{b) Communication}

Transfer of information between two ends is communication (Daryl, 2011). Communication is the most popular use of the Internet, since its inception electronic mail, or e-mail, has become a vital communication medium. It may be the most popular application of the Internet because it extends and enhances our ability to communicate with others but as we know communication via internet is very commonly used but it has its dark side too. During communication on the internet which is the public community based network, users specially women which are less aware with the latest hacking technologies have puts great care and attention while transferring their confidential data or accessing the files or browsing on the internet (Kumari et.al, 2004). They can't assume 
that their messages are private, so they should be careful about what they write.

\section{c) Social Networking}

In developing countries male dominated society social interaction of women is an effective tool for learning knowing their rights and pursuing their carrier (Arif Seema, 2011)

Some main advantages of social networking are

-keep in touch

-Get Feedback

-Share Multiple Points of View

-Talking to Other Students

-Stay in Touch Anywhere

\section{d) Transfer of Files}

There are so many options to transfer the files through internet. Like by the use of mail, through sky drive, etc. Now a day's file transferring makes a business man`s or women`s life much more easy they can transfer their files easily via internet now (Wijnholds, \& Little, 2007).

\section{e) Entertainment}

The thing which makes you happy whenever you use it, it gives you relaxation in tired mood is called entertainment (Greenwood, 2012). There are millions of ways of entertainment for you on internet. Example: social networking sites, films, cartoons, videos, songs, etc. Internet now can entertain person of any age group whether a child, a man or an old aged people all can pass their time happily on internet now.

\section{f) Internet Transaction \& Making Money}

An internet transaction is the sale or purchase of goods or services, whether between businesses, households, persons, government and organizations, through internet (Karine Perset, 2010). Online jobs are the best example to understand how to get money by the use of the internet. Now days internet is the biggest source of doing business and making money just by clicking, publishing the ads of their product on the websites online. It is one of the biggest achievements for those women who have talent of different things. 


\section{g) Marketing}

Different companies are using it for their marketing in order to save huge money. Pepsi by passed a super bowl advertisement for the first time in 20 years in order to shift millions of dollars into social media (Jeffery, 2011). The world of politics has seen its fair share of social media influence, from the often used example of the Obama campaign to the rise of conservatives on Twitter with their \# TCOT (top conservatives on Twitter) hash tag that has fueled the Tea party movement. Management of BBC has superimposed the policy on their staff that they must use the social media tools in-order to fulfill their job properly and effectively. As all women love shopping so marketing via internet become a good opportunity for sellers to sale via internet $\mathrm{n}$ easy for women who can't go market can buy via internet now.

\section{h) Online Education}

Now internet makes education free and easier to all. It's the place where we get information and knowledge about each and every thing (Teece, 2009). However it is a best source of getting education to those who can't go out for regular studies especially for women. Those women should achieve the credit for getting online education through different websites and can also give online exams (Rychetnik, 2002). (Fatima et al, 2002) reported almost $83.3 \%$ of users in Pakistan consider internet is a valuable source for knowledge.

\section{Background}

As our understanding amplifies, we are required to re-examine our existing beliefs- very often those beliefs are long-standing and held by many within society (Benjamin E, 2012). Social media touches nearly every facet of our personal and business lives. In businesses it is not only used for marketing but it is also a part of a company's overall strategy. Social media plays a vital role in every business success. It is living, breathing and it touches every part of an organization from customer service to sales, even HR and IT. Meaningful engagement, participation and the value creation rule the day of social media. You can easily transfer information through it to billions of people and raise your voice through this platform within no time. Accessibility and connectivity with people no longer needs much time and resources, but only a few minutes from your busy schedule. If you just spend half an hour a day using it, you are likely to be connected with others and can update your profile on different available social media tools. When the Iranian government closed all outgoing communication channels, a revolution within the country was made via Twitter. One of the key advantages of social media is enabling users to stay connected with friends and family who are geographically separated. This global connectivity exceeds to positive and negative messages relating to products and services. 


\section{Methodology}

A self-administered questionnaires based survey was conducted to more than 100 women from Karachi-Pakistan. As the internet is the medium for literate people so educated women comprising students, housewives \& the professionals were included in the survey. Female Student was selected from different departments of University of Karachi like computer science, statistics, mathematics, physics and dental education. Sir Syed University of Engineering and Technology, Jinnah University and Liaquat National Medical College, Govt. Degree College Gulshan-e-Iqbal, Khatoon-e-Pakistan Govt Degree College for women and Ranaliaquat Ali Khan Govt. Degree College for Home Economics. Therefore professional as well as non professional degrees students included in the survey.Questionnaire designed for this study contained more than 30 questions to determine general trend about the uses of internet among women as well as their vies about utility of this medium in education, research and social interaction

We conducted an online survey using Google docs. In this survey people of different fields participated. The questionnaire comprises of following types of important questions to address: Which market segment do you belong to? Technology in your view is; Do you like using technology to learn? Which technology has shaped your life in better way? What new technology could you not live without? How often do you access the Internet? If you use it every day how many hours do you use it for? What do you use the internet primarily for?

Local and international research reports and articles were referred as secondary source of information in the research report. Statistical analysis and data presentation tools were used to demonstrate the result

\section{Result and Discussion}

Result of the survey showed that $85 \%$ are using internet daily. Majority $(68 \%)$ of respondent were in age group of 18-24 years. About usefulness of internet $42 \%$ see it as source of education, $16 \%$ as social networking and $14 \%$ as entertainment and only $1 \%$ viewed as source of vulgarity. $66 \%$ agreed that information available on internet is reliable and useful. Similarly $82 \%$ participants viewed that internet is useful for female in Pakistan. $90 \%$ stated that internet is useful for women personal decision making like Buying Jewelry, cloth etc. The chi square test showed that frequency of use is dependent of age of the participant.

In male dominated society internet as a mean of empowerment of women which is supported by the survey finding almost $50 \%$ participant indicated internet as the cheapest source of information and $75 \%$ viewed as social interaction outlet for women. It is 
interesting to note that only $1 \%$ viewed internet as source of vulgarity in society suggesting positive influence of internet in Pakistan, particularly for women. Another important aspect revealed is, $73 \%$ of participant viewed that use of internet be linked with age group of user suggesting more adult participation. It is found that women are actively $(90 \%)$ using internet as their personal activities like shopping, entertainment etc. The result of the survey strongly support the argument that internet has a positive impact in Pakistan and is source of knowledge, education and social freedom for female in Pakistan.

Following are the graphs showing the percentage results obtained from the survey about the some important questions we asked.

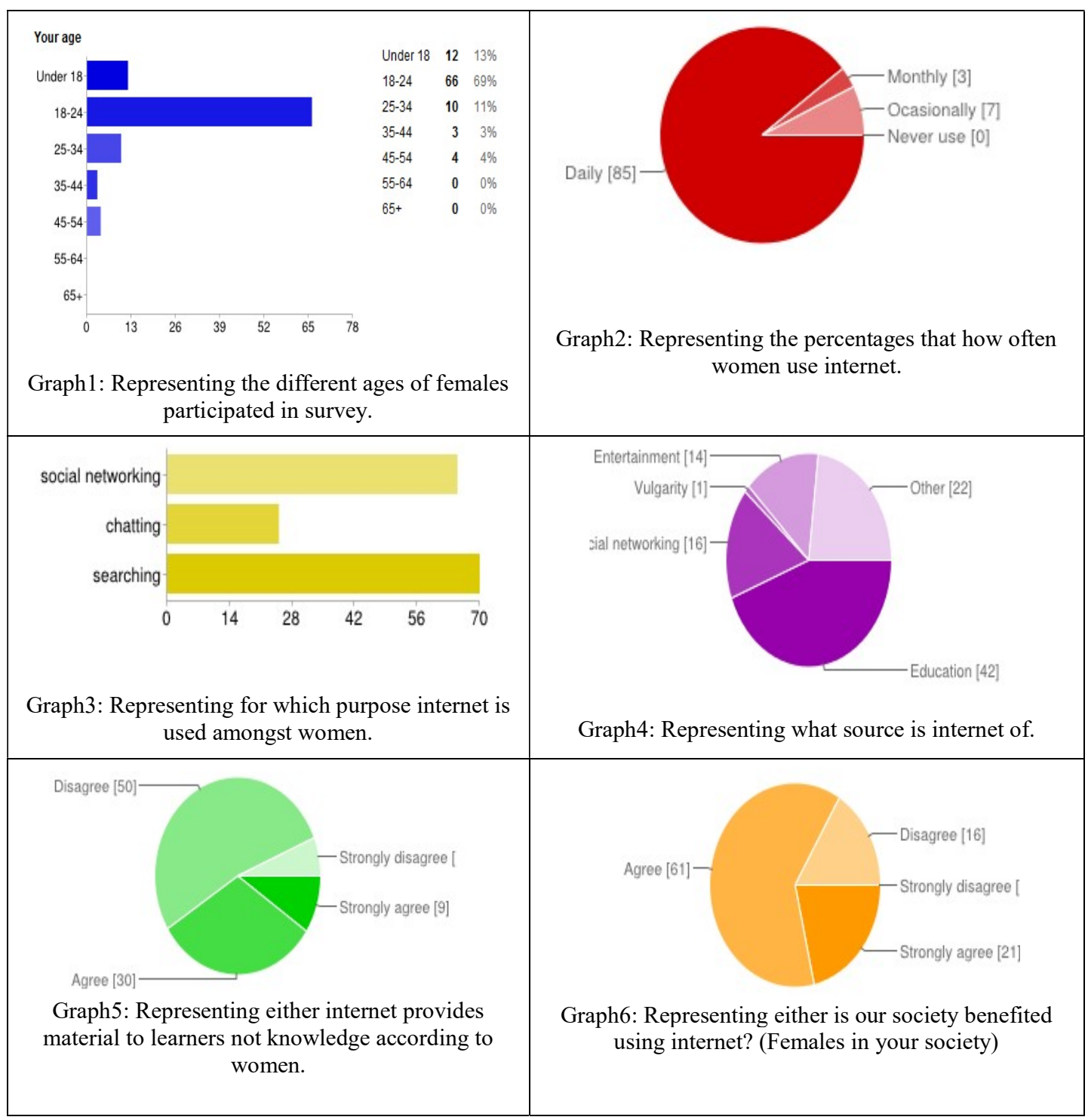




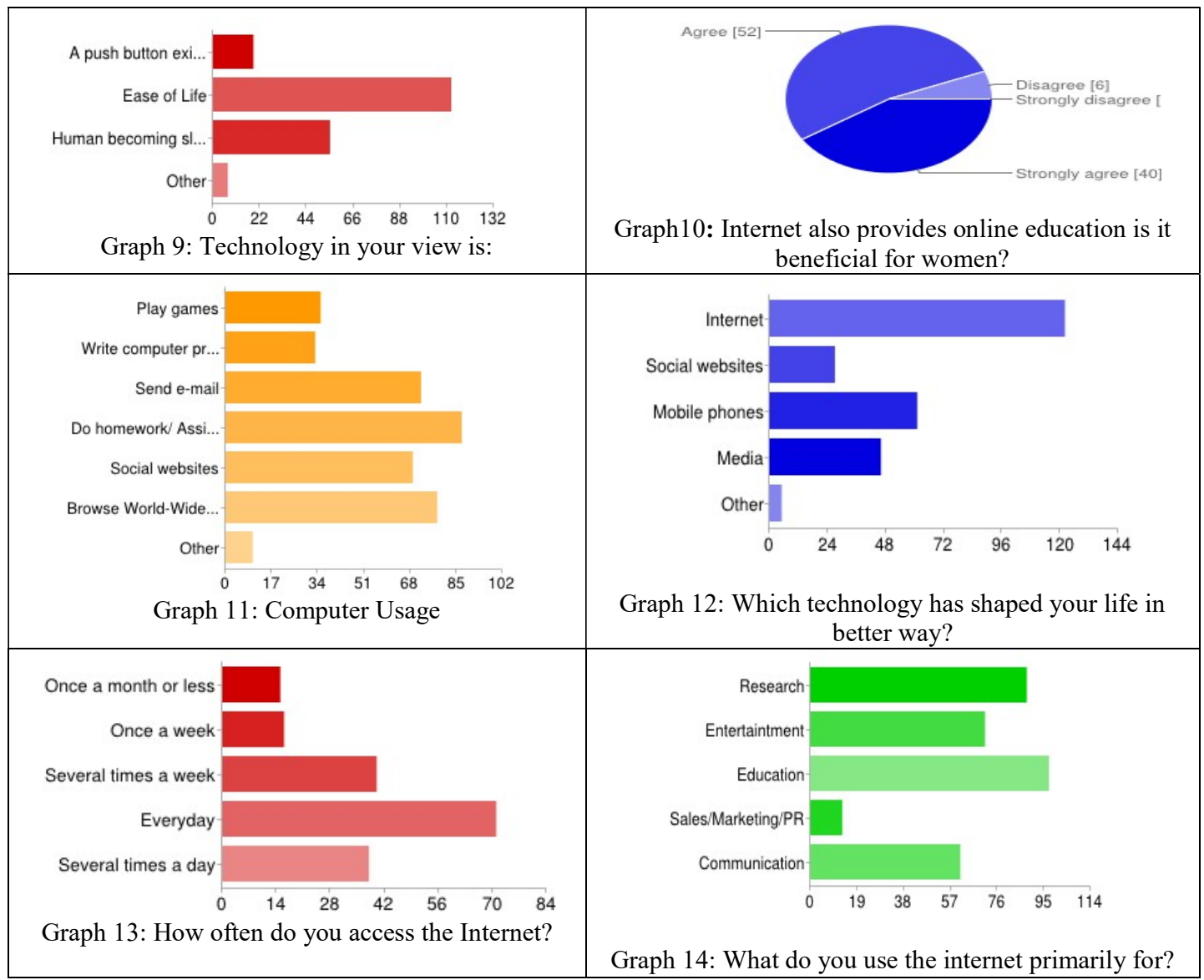

Figure 1: Statistics of Respondents

It may be concluded that now-a-days internet use has been more common and women in our society are much aware of using internet, its benefits and drawbacks are also known to them. Following points are showing the results of a survey conducted:

1. Most of the housewives and students use internet for searching and social networking purpose.

2. The internet is a useful tool for women in Pakistan for education, research and women empowerment

3. Chatting ratio has become lesser because of the popularity of social networking websites.

4. Women are becoming modernized using internet that they can stay updated about the latest trends in fashion.

5. Women can earn easily without going out for jobs as they could start their own business online.

6. Most of the women agree that there should be age boundaries for the allowance of using internet, because of the vulgarity spread through internet on a few websites. 
7. According to most of the women, information provided on internet is authentic.

8. Internet is widely used for the purpose of Education

9. To get social it's now easy because of women and it has also produced an ease for the women to stay connected to their family and friends easily and in a very cheap way.

10. Most of the women in Pakistan do not agree that the use of internet is only providing material to learners not knowledge.

\section{Conclusions}

Technology is the ease of life in view of the most of the participants and it shaped our life too. Almost all of the internet users are satisfied with the internet and its technology. Most of the people in our society use computers to do their assignments, do their home works and some people uses internet for browsing only. Most of the people in this modern era access internet daily for their social connections and for the education and research. After the survey it was concluded that in our society most of the students are using and utilizing the technology and according to most of the responses we have that the technology is good thing for the society. The life we have now a day's is better than the life which our grandparents spend due to the technological advancement. Most of the people in our society like to use technologies to learn many different things. People get confused when we ask them does the technology ever let you down. In our society now people realize that the computers are the basic need for our routine and office works and most of the people use internet 1-3 hours a day. Everything has its pros and cons; we have to weigh them and take advantage of the pros accordingly and the advantages of our digital age for communication are far too important to be marred by abuse. Anyway, as hackers find ways to defeat systems, so can security experts who maintain and patch them, to keep problems to a minimum. It is concluded that use of internet is not harmful it has got many uses of it but it depends upon the user only either they avail benefits or not. Internet usage is very common in the age of 18-24 women. Internet access does not guarantee to make us smarter. It is questionable whether the Internet makes you smarter or dumber. But certainly the benefits of internet depend on how users apply the information they get.

\section{References}

Aycock, J. \& J. Sullins, (2010), "Ethical Proactive Threat Research," Workshop on Ethics in Computer Security Research (LNCS 6054), New York: Springer, pp. 231-239.

Benjamin E (2012), "The Stabilizing Effects of International Politics on Bilateral Trade Flows", Word Count: 10,293. 
Daryl J. Bem (2011), "Feeling the Future: Experimental Evidence for Anomalous Retroactive Influences on Cognition and Affect", Journal of Personality and Social Psychology, Vol 100, DOI: 10.1037/a0021524, pp. 407-425.

Teece, David J. (2009), "Business Models, Business Strategy and Innovation”, Long Range Planning 43 (2009) 172e194, 0024-6301.

Fatima, Fakeeha et.al, (2010), "Impact and Usage of Internet in Education in Pakistan, European Journal of Scientific Research, Vol.47 No.2 (2010), pp.256-264"

H. Bouwman, T. Haaker \& M. de Reuver(2012), "Some Reflections on the High Expectations as Formulated in the Internet Bubble Era", Elsevier 0016-3287, pp 420-430.

Perset, Karine (2010), "The Economic and Social Role of Internet Intermediaries" OECD

Kumari , Meena Rajani \& M. S. Chandio (2004), "Use of Internet and its Effects on our Society" National Conference on Emerging Technologies, Institute of Mathematics and Computer Science, University of Sindh, Jamshoro, Pakistan

Rychetnik, L (et.al) (2002), "Criteria for Evaluating Evidence on Public Health Interventions", J Epidemiol Community Health2002;56:119-127.

Jeffery, Matthew (2011), A Vision for the Future of Recruitment: Recruitment 3.0

Nan Greenwood (2012), "Respite: Careers Experiences and Perceptions of Respite at Home BMC Geriatrics 2012, 12:42 doi:10.1186/1471-2318-12-42.

Park, Y. Heo, G. M., \& Lee, R. (2011). Blogging for Informal Learning: Analyzing Bloggers' Perceptions Using Learning Perspective. Educational Technology \& Society, 14 (2), 149-160.

Rehman, Kashif \& Nadeem Safwan (2010), "Students' Attitude towards the Uses of Internet", Iqra University Islamabad Campus, Pakistan, International Journal of Business and Management, Vol. 5, No. 6; June 2010

Arif, Seema (2011), "Broken Wings: Issues Faced By Female Doctors in Pakistan Regarding Career Development", International Journal of Academic Research in Business and Social Sciences August (2011), Vol. 1, Special Issue ISSN: 22226990, pp. 79-101. 
Wijnholds, H. \& Little, M.W. (2007). Online Gambling: Murky Legal Status and Vulnerable Socio-economic Environment Pose Public Policy Challenges. Journal of Internet Commerce, 6(1), 119-138.

Dr. M. Sadiq Ali Khan is Assistant Professor in the Department of Computer Science, University of Karachi. 